\title{
The Structural Imbalance of China 's Banking Currency Mismatch Li Yuan
}

School of Economics and Trade, South China University of Technology, Guangzhou, Guangdong, China

Keywords: Commercial bank; currency mismatch; structural imbalance

Abstract. Since the reform of RMB exchange rate formation mechanism in 2005, the currency mismatch in the banking industry makes the change of exchange rate an important factor affecting the banking operation. This paper analyzes the currency mismatch of 16 listed banks in China, and points out that there are serious currency mismatches in China's banking industry, and there are obvious differences in the degree of currency mismatch in the banking industry. The main reason is that a series of historical reasons such as the single subject of China's foreign exchange market, the arbitrage behavior of commercial banks under the expected appreciation, and the initiative arbitrage behavior of commercial banks. It is suggested that both the regulatory authorities and the commercial banks should pay attention to the phenomenon of currency mismatch in the macro-prudential supervision, establish the currency mismatch risk early-warning mechanism and perfect the financial market to hedge the exchange rate risk.

\section{我国银行业货币错配的结构性失衡问题}

\author{
李媛 \\ 华南理工大学经济与贸易学院, 广州, 广东, 中国
}

关键字：商业银行；货币错配；结构性失衡

中文摘要: 自从我国从 2005 年进行人民币汇率形成机制的改革后，银行业货币错配的存 在使得汇率变动成为了影响银行业经营的重要因素。本文分析了我国 16 家上市银行的货币错 配状况, 认为我国目前银行业存在着严重的债权性货币错配, 并且银行业内部货币错配严重 程度存在明显差异, 产生的主要原因在于我国外汇市场主体单一等一系列历史原因、商业银 行客户在人民币升值预期下的套利套汇行为、以及商业银行主动的套利行为, 为此笔者认为 监管部门和商业银行管理层都应该及时关注货币错配这一现象, 将其纳入宏观审慎监管的范 畴、建立货币错配风险预警机制、健全金融市场以对冲汇率风险。

\section{一、引言}

人民币汇率制度改革从 2005 年正式起步，开始实行以市场供求为基础、参考一篮子货币 进行调节、有管理的浮动汇率制度, 汇率的双向波动幅度逐步扩大, 进而使得我国商业银行 面临的汇率风险加大。近期由于美国经济的复苏等多方因素叠加, 美元持续走强, 全球各新 兴经济体货币受其影响持续走弱, 人民币也不能置身事外。同时我们也看到汇率波动日益频 繁, 并且对经济的影响越来越大。作为中国经济的供血部门的银行业, 汇率变化对其的影响 成为了值得研究的问题。

正是由于银行业的存在着货币错配现象, 才使得汇率风险成为银行业不得不面临的市场 风险之一。货币错配的定义目前学界通用的是 Goldstein\&Turner 在 2005 年阐述的定义: 由 于一个权益主体（包括主权国家、银行、非金融企业和家庭）的收支活动中使用了不同的货 
币计值，其资产和负债的币种结构不同导致其净值或净收入对汇率变化的敏感现象。从不同 的角度, 货币错配的具体形式也不同。从存量角度看, 货币错配是指资产负债表对汇率变动 的敏感性; 从流量角度看, 货币错配是指损益表和现金流量表对汇率变动的敏感性。货币错 配的类型有两种, 分别是债务性货币错配与债权性货币错配。不同类型的货币错配风险是不 一样的, 债务性的货币错配是指某个经济主体所拥有的外币资产小于其所需要偿付的外币负 债, 其风险在于当本币贬值时, 因为此时该经济主体需要付出更多的本币; 而债权性的货币 错配是指一个经济主体所拥有的外币资产大于外币负债的情形，其风险在于本币升值。

银行业的货币错配比一般企业更复杂, 对其进行考察有必要考虑两类错配：直接货币错 配和间接货币错配, 这两类错配都暴露于汇率水平变动的风险中。直接货币错配是指存在于 银行自身的资产负债表中，作为银行资金来源的计价货币与资金运用的计价货币不匹配; 而 所谓间接货币错配是指银行的客户的资产负债表中, 其自身的资产和负债的计价货币出现了 不匹配情况。间接货币错配会使得银行业受损的原因在于, 如果银行客户的货币错配导致客 户资产大量损失或者资不抵债而破产, 则会使银行的资产质量降低, 从而给银行造成比较的 损失, 也有可能引发银行业的整体危机。本文主要研究的是银行业的直接货币错配问题。

\section{二、文献综述}

国内关于汇率变动对微观主体的影响方面所进行的研究较少, 特别是汇率变动对金融体 系的影响。唐伟霞和朱超（2007 年）研究了银行部门货币错配与净值的关系, 认为二者关系 显著; 周好文和刘飞（2008 年）通过运用资本市场法和现金流量法对中国上市银行的汇率风 险进行实证分析, 发现中国的银行业面临显著的汇率风险; 张正平 (2009) 研究了汇率变动 对银行业的影响, 得出的结论是人民币汇率变动对我国的国有商业银行的负面影响大于对股 份制商业银行的影响，同时人民币汇率与股份制商业银行的股价不存在显著的协整关系和 Granger 因果关系; 陈晓莉和杨杨（2010 年）利用上市银行的财务数据检验了货币错配的资 产负债表效应, 其结果证明这种效应确实存在, 但是存在滞后性; 李雪莲等（2010 年）运用 修正后的资本市场法对我国商业银行的汇率风险进行了估计，实证结果表明 70\%以上的商业 银行汇率风险显著; 江百灵和叶文娱（2012 年）构建了本币升值通过银行资产负债表渠道引 起银行危机的模型, 认为货币错配风险对我国商业银行的稳定性有不利影响; 宋帅邦和崔建 鹏（2014 年）分析了货币错配对我国商业银行净利润的影响, 认为商业银行的货币错配程度 与盈利能力之间存在着明显的负相关关系。

综上所述, 目前为止, 对我国银行业货币错配的研究主要集中在宏观层面, 对银行业中 具体单个银行进行分析的文章较少。因此, 本文主要对 16 家上市银行的财务报表进行分析, 试图剖析汇率变动对商业银行资产负债表、利润表和现金流量表的影响, 以提醒各家银行注 意货币错配这一现象的存在及其影响力, 并分析了产生的原因, 同时在此基础上提出了防范 银行业货币错配风险的措施。

\section{三、我国银行业的货币错配现状分析}

正如前文所提到的, 本文以下将从流量和存量两个方面考虑分析汇率变化对我国商业银 行货币错配的影响。鉴于数据的可得性及代表性, 本文选取的样本是目前在中国资本市场公 开上市交易的 16 家商业银行。同时由于我国从 2005 年开始人民币汇率改革, 实行有管理的 浮动汇率制度, 从而使得商业银行真正面临汇率风险, 故样本数据的时间范围为 2005 年至 2014 年。 


\section{（一）银行汇兑损益状况}

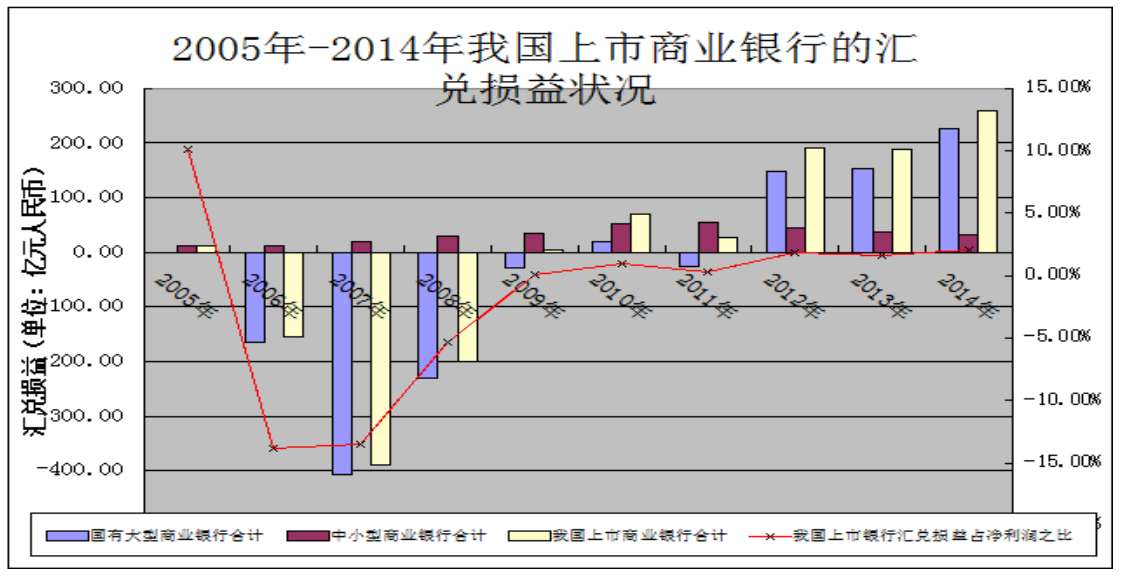

图 12005 年-2014 年中国上市银行的汇兑损益及其占当年净利润之比的状况

数据来源：上市银行各年公布的年报中的利润表、笔者自己整理

注: 以上数据具体包括: 平安银行、浦东发展银行、华夏银行、民生银行、招商银行 2005 年至 2014 年的 数据; 中国工商银行、中国银行、兴业银行 2006 年至 2014 年的数据; 中国建设银行、中国交通银行、宁波银 行、南京银行、北京银行、中信银行 2007 年至 2014 年的数据; 中国农业银行、光大银行 2010 年至 2014 年数 据。（如无特殊说明，下同）

商业银行货币错配比较直观的一个衡量指标是来自银行利润表的汇兄损益的变动情况。 汇兑损益是货币错配引起的一个结果, 通过各银行汇兑损益的变动情况可以反向衡量其货币 错配的大小和方向。汇兑损益所反映的汇率风险是已经发生的损益。

图 1 反映了 2005-2014 年 16 家上市商业银行的汇兄损益情况。从图 1 可以看出，16 家 上市商业银行从 2005 年至 2014 年的汇兑损益的情况可分为两个阶段, 第一阶段为 2005 年至 2008 年，第二个阶段为 2009 年至 2013 年。第一阶段总体上主要表现为汇兑损失，且汇兑损 失先扩大再缩小, 其绝对值比较大, 最高值为 2007 年的 389.11 亿元。同时, 汇兑损失占当 年净利润的比例也较大, 在 2006 年其达到了最高值, 为 $13.88 \%$, 这意味着在 2006 年仅仅因 为汇率的变动, 就使得这 16 家上市商业银行净利润的 $13.88 \%$ 被吞噬殆尽。

如果对我国上市的 16 家商业银行进行分类，可以分为 5 家国有商业银行和 11 家股份制 商业银行，这两类商业在汇兑损益方面表现出不同的趋势。国有商业银行的汇兑损益在 2005 年至 2009 年为汇兑损失, 从 2010 年开始逐步回升为汇兄收益, 且其波动幅度相当大, 这说 明我国国有商业银行受汇率的影响较大, 究其原因在于国有商业银行本身的外币资产和外币 负债规模大，涉外业务较多，同时由于离汇改起步时间不长，在管理汇率风险方面的经验与 相关人才都是不足的。相比之下，我们可以看到，11家上市的中小型股份制商业银行的汇兄 损益之和一直为正, 即一直为汇兑收益, 但是绝对值一直很小, 这与股份制商业银行本身的 外币资产和外币负债的规模小，其涉外业务较少有关。 


\section{（二）银行外币现金流对汇率的敏感性分析}

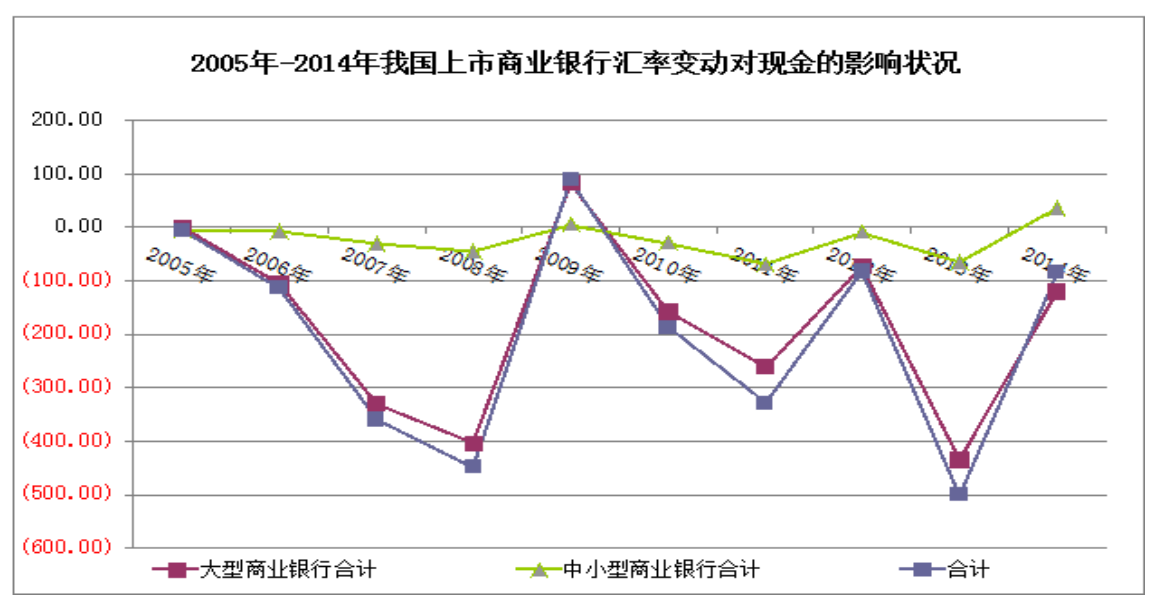

图 22005 年-2014 年中国上市商业银行汇率变动对现金的影响状况

数据来源: 上市银行各年的现金流量表

在上市银行的各年年报中，来自现金流量表的汇率变动对现金的影响是反映银行货币错 配情况的另一项目。根据企业会计准则的要求，银行外币现金流量及境外子公司的现金流量 折算成人民币时，所采用的是现金流量发生日的即期汇率或平均汇率，而现金流量表中另一 个项目—— “现金及现金等价物净增加额” 中外币现金净增加额是按期末汇率折算的, 这两 者的差额就是汇率变动对现金的影响。

图 2 整理了从 2005 年至 2014 年各上市商业银行的汇率变动对现金影响状况。从图 2 可 以看出, 2005 年至 2014 年间汇率变动对现金的影响存在差异，但是基本上表现为损失，尤 其是近年来更加如此。这一现象的出现与当今世界的货币体系有明显的联系。由于目前的主 导货币是美元，即国际贸易间结算与支付货币基本上是美元，因此我国商业银行的外币现金 流也基本上以美元为主。同时，自 2005 年汇改启动以来，随着人民币双向汇率波动幅度的不 断扩大，之前被固定汇率制度抑制的人民币汇率越来越趋于其真实汇率，长期以来国际贸易 的 “双顺差” 导致的人民币对美元的升值趋势日益显现。这样一来，美元对人民币是贬值趋 势，故当美元兑换成人民币之后，反映在报表上就变成了汇率变动对现金的影响为负值。

从各家商业银行对比来看，汇率变动对现金的影响较大的有中国银行与工商银行，且一 直都是负值; 影响最小的则是华夏银行。总体上来看, 5 家国有商业银行受汇率变动的影响 大于 11 家股份制商业银行，其原因与银行的业务类型和涉外业务的规模有关。具体来说，大 型国有商业银行的外币业务较中小型股份制商业银行更多，且规模更大。截止 2013 年年末， 16 家上市商业银行的现金流均受到汇率变动的负面影响，总影响合计达到 500 亿元人民币， 其中承受汇率变动对现金流的负面影响最大的银行是中国银行，金额达到 228 亿元人民币; 受汇率变动的负面影响最小则是华夏银行，仅有 600 万元人民币。由此可见，一方面人民币 汇率日益频繁的波动给上市商业银行的现金流管理带来了新的挑战; 另一方面，相比股份制 商业银行，国有商业银行所承受的汇率风险更大，需要引起管理层更大的重视。 


\section{（三）银行外汇敞口净头寸的变化}

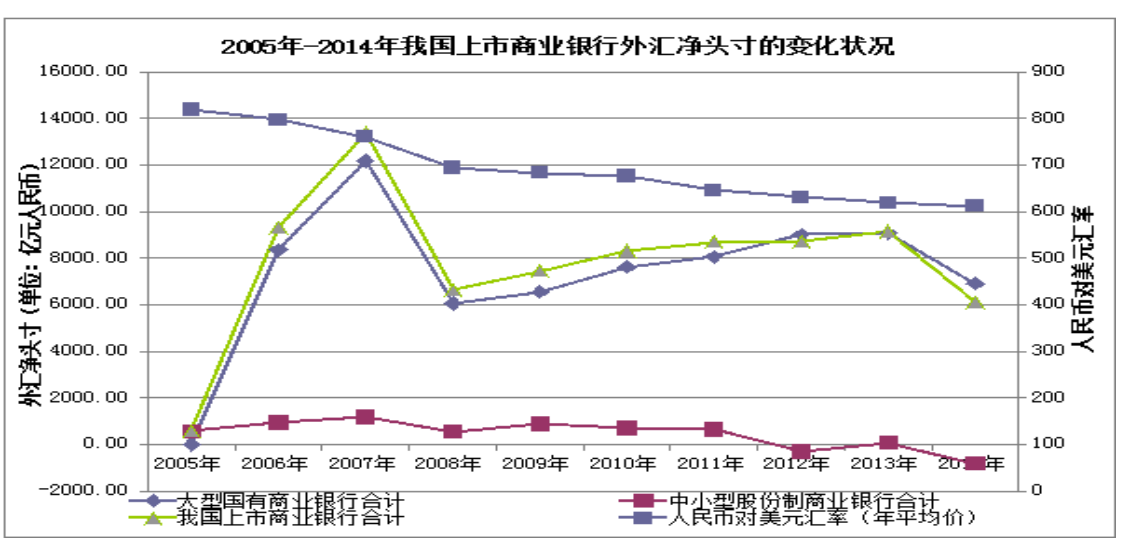

图 32005 年至 2013 年中国上市商业银行的外币净头寸状况（单位：亿元人民币）

数据来源：外币净头寸来自于上市商业银行的各年年报; 人民币对美元的汇率（年平均价）来自《中国统 计年鉴 2014》

注：由于我国上市银行的外币币种以美元为主，故此表格仅考虑美元的情况；

图 3 是 16 家上市商业银行的外币净头寸（即外币总资产减去外币总负债）的情况。从整 体上看, 我国上市银行的外币净头寸变化趋势可以分为两个阶段, 在 2005 年至 2007 年这一 阶段内, 我国国内金融改革不断深化, 各家商业银行都对金融市场看好, 加快对海外市场的 进军, 故外币净头寸呈现不断快速上升的趋势; 在 2008 年是个显著的转折点, 外币净头寸明 显下降，这与由美国 2008 年次贷危机而引发的全球性金融海啸有关; 之后一直到 2014 年， 随着全球金融市场的缓慢恢复，外币净头寸表现出缓慢的上升趋势。

从各家上市商业银行对比的角度上看, 16 家上市商业银行的外币净头寸大部分表现为正, 即外币资产大于外币负债，也就是说我国上市银行的货币错配基本上表现为债权性货币错配， 在人民币升值的趋势下, 商业银行的外汇净头寸面临外汇资产贬值的风险, 在商业银行不做 任何防范措施的情况下，使得我国银行业面临相当大的外汇损失。再仔细分析各个上市商业 银行 2005 年至 2014 年的外汇净头寸的变化趋势, 我们可以发现中小型股份制商业银行的外 币净头寸绝对值不大, 且可以较为灵活的调整, 能够利用人民币升值的趋势, 使得自己持有 的外币负债高于外币资产，从而获利; 相比之下，国有股份制商业银行由于规模太大，即使 看到这个套利机会的存在, 也无法在短时期内做到使美元负债高于美元资产, 不能享受到人 民币升值的好处，相反必须承担相应的债权性货币错配的损失与风险。

以上分别从三个角度, 分析了汇率变动对商业银行经营的影响, 可以得出以下结论：一 由外币净敞口指标的数据结果可知, 中国上市商业银行整体上存在严重的货币错配, 尤其是 5 家大型国有商业银行的货币错配状况更加严重, 同时基本上是债权性的货币错配; 二由汇 兄损益、汇率变动对现金的影响指标可知, 因为货币错配的存在, 使得汇率变动对我国上市 银行的盈利水平造成了严重的影响; 三从大型国有商业银行与中小型股份制商业银行的比较 来看, 可以发现银行业内部存在着结构性失衡现象, 即国有商业的汇率风险更大, 货币错配 情况更严重，对商业银行经营影响更大，这样对管理层管理汇率风险提出了更大的挑战。

\section{四、商业银行货币错配的原因分析}

\section{（一）我国外汇市场主体的单一性}

由于从改革开放以来, 我国实施出口导向型政策以及出台多项政策吸引外资, 使得我国 从 1999 年至 2011 年连续 12 年保持经常项目和资本项目双顺差; 同时, 由于目前是以美元、 欧元和日元为主要结算货币的世界货币体系, 对于中国这类本币不是主要结算货币的国家而 
言, 对外开放程度的提高必然离不开货币错配现象的出现及货币错配程度的加深。另外, 我 国外汇市场发展不完善, 外汇交易主体单一, 以商业银行为主, 导致几乎所有的外汇流入通 过商业银行体系转化为央行的外汇储备，即遵循了图 3 所示的流入路径。截至 2014 年年末， 我国的外汇储备余额高达 3.84 万亿美元。中国从 1994 年开始实行强制结售汇制度, 当时将 外汇视为稀缺资源, 各经济主体对于所需与所得外汇必须向银行买卖, 这样就使得本应该由 各经济体自主承担的货币错配风险转移给了银行部门, 加剧了银行业的汇率风险。虽然自 2007 年以来, 我国逐步放松对经常项目的外汇管制, 允许境内机构自行保留经常项目的外汇收入, 但是在人民币升值的预期之下，各经济体本着理性的原则仍然会选择出售外汇，持有本币。 这样一来, 商业银行的外汇存款表面是一增一减相抵, 外汇存款余额表现平稳, 实际上流入 的外汇存款大量转换成人民币存款, 使得我国商业银行的本外币资产负债配置进一步发生改 变。

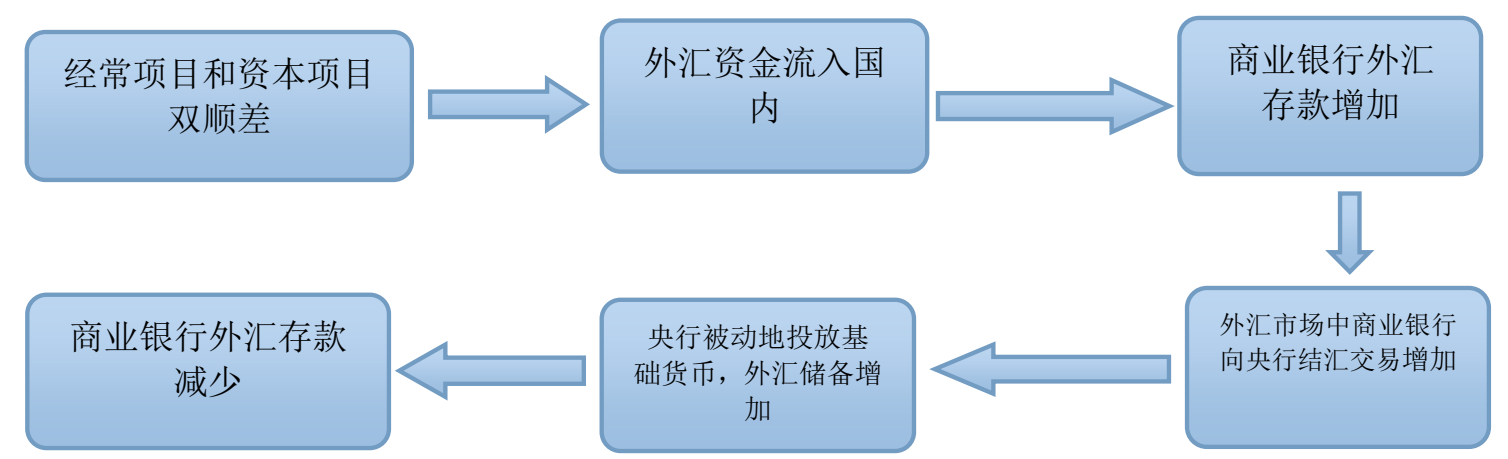

图 4 外汇流入路径图

\section{（二）商业银行客户在人民币升值预期下的套利套汇行为}

自 2005 年我国汇率体制改革以来，我国开始实行有管理的人民币浮动汇率制度，人民币 汇率波动幅度增大，人民币进入持续升值预期通道。以美元对人民币的汇率变化趋势为例， 根据中国外汇管理局公布的数据, 2005 年人民币对美元汇率的年平均价为 819. 17, 而在 2013 年这一数值为 619.32 , 名义汇率升值了 $24.40 \%$ 。

人民币升值预期下的套利套汇行为主要是通过中国大陆在岸人民币金融市场和香港联人 民币市场之间的资金运动形成的。具体来说, 由于中国国内人民币利率和汇率形成机制尚未 完全市场化, 使得各经济主体可以利用离岸市场与在岸市场人民币对美元的现汇汇价的差异, 以及持续的人民币升值预期从中套汇; 同时，利用离岸市场和在岸市场的利率差异从中套利。 根据张明、何帆 (2012) 的研究, 他们认为套汇行为主要有两种方式, 一是利用在岸与离岸 市场现汇价差，其证据为离岸与在岸两个市场的人民币现汇汇价之差与香港人民币存款月度 增量、人民币结算实际收付比都呈明显的正相关; 二是利用持续的人民币升值预期套汇, 其 证据是香港人民币月度存款增量与香港市场上的人民币升值预期呈现出正相关关系。套汇行 为也主要有两种方式, 一是基于人民币信用证的内保外贷方式, 其结果为自香港银行可以向 本地企业发放人民币贷款以来, 香港银行对内地的净债权规模猛增; 二是内地企业在港发行 人民币债券, 其证据为在香港发行人民币债券的企业中, 来自内地的企业占比高, 据马骏

（2012）的估算，这一比例达到 80\%。

\section{（三）商业银行本身主动进行货币错配}

近年来，我国商业银行国际化经营趋势日益显著，以中国工商银行为例，2014 年中国工 商银行在英国《银行家》杂志按银行一级资本排名中蝉联第一名。截止 2014 年年末，中国工 商银行境外机构有 338 家, 分布在 41 个国家和地区，境外机构员工达到 11759 人，境外客户 存款达 5735 亿元, 占客户存款的比例为 3. 7\%, 境外贷款达 9293 亿元, 占总贷款的比例为 $8.4 \%$ 。 另外，2005 年至 2014 年中国工商银行的境外存贷款规模均增长了近 9 倍，且占客户存贷款 
的比例均呈现逐年上升的趋势。

我国商业银行出于自身经营的需要, 尤其是在目前银行国际化经营的趋势日益突出的情 形下, 一方面, 商业银行因为经营着涉外业务, 因此需要持有一定数量的外币资产, 这样会 加剧货币错配; 另一方面，商业银行可以利用自身的资金、技术、信息和人才方面的优势， 主动承担企业和居民个人的货币错配风险, 即接受商业银行各户对于外汇的结售汇请求, 改 变自身的资产负债本外币结构。例如, 在人民币升值的趋势下, 商业银行可以利用金融衍生 工具主动进行外币资产和负债的合理配置, 控制外币资产增加的速度, 甚至使得外币资产小 于外币负债, 从而获得本外币利差和汇差。

\section{五、商业银行货币错配可能导致的风险}

\section{（一）影响商业银行的盈利水平}

不同汇率变动背景下，不同类型的货币错配对某一经济体的影响性质不同。尽管从 2013 年下半年以来, 美元有所升值, 人民币中断了一路升值的趋势, 但是与 2005 年的币值相比, 人民币确实是升值了, 美元相对贬值了, 而之前整理的数据可知我国主要的货币错配类型为 债权性货币错配, 因此, 人民币的升值对商业银行经营产生了不利影响, 使其利润降低, 强 化商业银行的金融脆弱性。以工商银行 2014 年年末持有的外汇净头寸为例，当美元兑人民币 贬值 $1 \%$ 时，其净利润将下降 0.42 亿元人民币。随着我国汇率形成机制朝着市场化方向的进 一步改革, 汇率弹性会日益增强, 双向浮动特征进一步明显, 虽然从绝对数量来看, 汇率的 小幅波动对利润表的影响并不严重, 但在持有外汇头寸增加和汇率发生较大波动时, 汇率变 化对利润的影响可能显著加大。

\section{（二）商业银行受到间接冲击的风险增加}

在人民币升值的预期下，企业和居民个人采取 “资产本币化，负债外币化” 的运作模式 是符合理性原则的, 但是这种模式也会导致其自身的货币错配程度加深。具体来说, 目前我 国从事外汇交易的企业和居民存在着明显的债务性货币错配现象，而作为其交易对手的商业 银行则相应存在着债权性货币错配现象。如果人民币继续升值, 这一现象会使得银行损失利 润, 而企业和居民获得套汇的收益。然而, 一旦人民币贬值, 以外币计价的债务合约会加重 企业的债务负担, 再加上我国外汇市场中避险的金融工具不够丰富, 企业利用金融工具的能 力也不够, 企业很可能面临破产的危险, 将难以归还银行贷款。当这种微观经济体的货币错 配风险叠加和传导到宏观层面, 就很可能形成系统性的货币错配风险并对商业银行造成冲击, 1997 年的亚洲金融危机就是前车之鉴。

\section{（三）金融市场调控的有效性降低}

由图 4 所示的外汇流入路径可知, 在商业银行存在债权性的货币错配情况下, 最终央行 成为银行间外汇市场的最大买家, 在没有采取相应的对冲措施或者对冲不充分的情况下, 外 汇储备的增加必然引起国内基础货币投放的增长, 最终可能带来通胀压力。在面临经济衰退 和国外需求减少时, 央行一般会降低利率, 这样对内可以刺激国内投资需求, 对外能让本币 适度贬值, 增加出口需求。但在货币错配的情况下, 本币贬值会使得存在债务性货币错配的 企业净值大幅缩水, 外币负债增加, 陷入财务困境, 甚至破产, 企业的破产会对商业银行造 成不利影响。因此，以利率作为调控工具的货币政策的有效性可能降低。

\section{六、政策建议}

\section{（一）监管部门要加强对货币错配的宏观审慎监管}

监管部门应该建立货币错配风险预警系统, 设立指标监测社会各部门的货币错配程度, 
尤其要预防人民币币值的突然暴跌; 将货币错配纳入到宏观审慎监管体系内, 尽可能地使外 币资产与负债的币种分布结构相匹配。

\section{（二）进一步丰富金融衍生工具市场}

货币错配持续加深的一个原因在于我国目前用于避险和对冲的金融工具不足。这使得银 行和企业在面对汇率风险时, 不能够及时有效低成本地将货币错配风险转移出去, 从而被动 地保留大量的外汇风险敞口。因此, 应当进一步扩大银行间外汇市场主体, 放宽准入条件, 鼓励更多的主体进入市场; 同时, 要加快衍生工具创新, 为外汇市场提供更多的对冲保值工 具, 避免货币风险敞口不断积累。

\section{（三）商业银行要加强货币错配的风险识别，及时调整资产负债结构}

商业银行要积极运用各种手段来降低货币错配风险, 比如限额管理、头寸管理和风险对 冲等。通过制定严格的限额, 将外汇交易头寸限制在可承受的范围内。对结构性外汇头寸运 用金融衍生工具如外汇远期交易、外汇期权、外汇期货、货币互换进行套期保值。利用外汇 敞口分析、情景模拟分析、压力测试和 VaR 等方法定期对外汇敞口净额进行汇率敏感性分析, 并根据汇率变动趋势对外汇敞口进行相应的调整, 合理安排外币资金的来源和运用以最大限 度地减少潜在的货币错配。要积极帮助客户抵消风险敞口，对客户以外币标价的贷款的投向 和运用进行不定期和定期的监控, 评估客户的违约可能性, 并将这种违约可能性作为对该企 业发放贷款的考量因素，以激励企业更好控制自身的敞口风险。

\section{（四）我国必须坚定地逐步推进人民币国际化}

仅仅靠银行体系来防范货币错配风险是不够的，应该继续深化人民币汇率改革，扩大汇 率浮动区间, 坚定不移地推进人民币区域化和国际化, 推动产业结构调整升级, 提升经济主 体竞争能力, 从根本上降低货币错配的风险。

\section{References}

[1] Xiaoli Chen and Yang Yang, The Effect of Foreign Exchange Rate Fluctuation on Banking Performance, Finance Forum, vol.11,pp.22-28,2010

[2] Bailing Jiang and Wenyu Ye, The Impact of RMB Appreciation and the Banking Crisis: China 's Experience from the Perspective of Currency Mismatch, Economic Survey,vol.6, pp. 156-160, 2012.

[3] Mei Xu, On Currency Mismatch and Term Mismatch in China's Banking Industry under the Impact of Exchange Rate - An Analysis Based on Bank's Balance Sheet, On Economic Problems, vol.6, pp. 84-87, 2010.

[4] Dejin Zhang and Jinliang Li, Risks and Countermeasures of Currency Mismatch of Commercial Banks in the Background of Exchange Rate Fluctuation, Financial Theory \& Practice, vol.3, pp. 59-64, 2014.

[5] Shuaibang Song and Jianpeng Cui, The Impact of Currency Mismatch on the Profitability of Commercial Banks, Finance Forum,vol.3,pp.40-49,2014

[6] Zhengping Zhang, An Empirical Study on Exchange Rate Risk of Listed Commercial Banks in China - Based on the Data Analysis since the Exchange Rate Reform in 2005, Journal of Beijing Technology and Business University(Social Science), vol.3, pp. 64-70, 2009. 